\title{
Dispensed Amount
}

National Cancer Institute

\section{Source}

National Cancer Institute. Dispensed Amount. NCI Thesaurus. Code C78721.

The quantity of a product that has been dispensed. 